FORMATION Formation emploi

Revue française de sciences sociales

129 | Janvier-Mars 2015

Pêle-Mêle

\title{
Edito : Relations formation, travail et emploi : explorer de nouvelles facettes
}

Jean-Frédéric Vergnies

\section{(2) OpenEdition}

1 Journals

Édition électronique

URL : http://journals.openedition.org/formationemploi/4339

DOI : 10.4000/formationemploi.4339

ISSN : 2107-0946

Éditeur

La Documentation française

Édition imprimée

Date de publication : 1 mars 2015

Pagination : 1

ISSN : 0759-6340

Référence électronique

Jean-Frédéric Vergnies, «Edito : Relations formation, travail et emploi : explorer de nouvelles facettes

», Formation emploi [En ligne], 129 | Janvier-Mars 2015, mis en ligne le 01 mars 2017, consulté le 30

octobre 2020. URL : http://journals.openedition.org/formationemploi/4339 ; DOI : https://doi.org/

10.4000/formationemploi.4339

(c) Tous droits réservés 


\title{
Relations formation, travail et emploi : explorer de nouvelles facettes
}

\author{
Jean-Frédéric Vergnies \\ Rédacteur en chef
}

La question de l'emploi est cruciale dans nos sociétés de chômage de masse, et la formation est souvent présentée comme une solution, notamment pour les jeunes. Pourtant, dans les relations complexes entre la formation, l'emploi et le travail, de nombreuses facettes sont peu ou pas explorées.

Ainsi en est-il des stages, présentés comme une panacée pour l'nsertion professionnelle. Malgré cela, la qualité et les effets des stages sont en fait peu connus (Dominique Glaymann).

À l'inverse, les contrats temporaires sont souvent peu appréciés. Toutefois, dans certaines configurations, dans l'agriculture notamment, ils permettent d'acquérir une expérience reconnue qui se traduit par une certaine stabilité dans l'emploi, à défaut de stabilité des emplois (Sonia Bellit).

À l’nstar des stages, l'appel à la professionnalisation des formations est général. Pour autant, au Québec, l'enjeu de la professionnalisation à l'université, bien que présent, reste relatif (Pierre Doray, Émilie Tremblay, Amélie Groleau). On peut certainement faire des parallèles avec la situation française.

Dans le modèle français, pour l'élite des grandes écoles, l'insertion semble assurée. Cependant, de nombreuses inégalités de carrières subsistent entre anciens élèves des Écoles normales supérieures (ENS), selon le sexe et l'origine sociale (Pierre Bataille).

Ainsi, évaluer les relations entre formation, travail et emploi soulève de nombreux défis, aussi bien éthiques que pratiques (Lucie Aussel) ${ }^{1}$.

Bonne lecture.

1 Ce texte et ceux de D. Glaymann, et de P. Doray et alii sont issus du séminaire du Réseau Évaluation Formation Emploi (EFE), "Quelles évaluations pour quelles professionnalisations à l'université ? ", qui s'est déroulé les 24-25 Octobre 2013 (à paraître dans la collection Net.doc du Céreq). 